\title{
Pathological laughter as prodromal manifestation of transient ischemic attacks - case report and brief review
}

Adriana O. Dulamea ${ }^{1,2^{*}}$, Costel Matei ${ }^{1,3}$, loana Mindruta ${ }^{1,4}$ and Virgil lonescu ${ }^{5}$

\begin{abstract}
Background: Based on a case report, the authors reviewed the data about involuntary emotional expression disorder (IEED). IEED includes the syndromes of pathological laughing and crying (PLC) and emotional lability (EL). PLC is a rare disorder of emotional expression characterized by relatively uncontrollable episodes of laughter and crying or both that do not have an apparent motivating stimulus.
\end{abstract}

Case presentation: Authors report the case of a 59-year-old man who presented with recurrent episodes of PLC of approximately 2 min duration, consisting of accelerated breathing, emission of guttural, snoring sounds, frowning of the eyebrows, followed by laughter accompanied by motor restlessness of all four limbs. PLC episodes preceded left carotid transient ischemic attacks (TIA's) manifested by reversible aphasia and right hemiparesis.

Electroencephalography performed during PLC episodes revealed no spike-wave activity. Brain magnetic resonance imaging showed lacunar infarcts in the left lenticulo-capsulo-thalamic area and multiple round lesions in the cortical-subcortical and in the deep white matter of frontal-parietal-occipital lobes bilaterally, with T2 hyperintensity, $\mathrm{T} 1$ isointensity and no diffusion changes. The episodes were interpreted as transient ischemic attacks although gelastic seizures could not be excluded. The etiological investigations revealed unstable plaques on the left carotid artery bulb and the aortic arch and a degenerative mitral valve stenosis. The patient was treated first with antiplatelet therapy and antiepileptic drugs but PLC stopped only after anticoagulation was started. During followup the patient continued to have left carotid and vertebrobasilar TIA's being on oral anticoagulation. The patient became asymptomatic only after mitral valve replacement was performed.

Conclusions: This case illustrates the difficulty distinguishing between gelastic epilepsy and TIA's in cases of PLC episodes and discuss the neuroanatomic bases and pathophysiology of this rare condition.

Keywords: Involuntary emotional expression disorder, Pathological laughter, Gelastic seizures, Transient ischemic attacks

\section{Background}

Involuntary emotional expression disorder (IEED) includes the syndromes of pathological laughing and crying (PLC) and emotional lability (EL) [1]. PLC is an exaggerated, uncontrollable and inappropriate laughter or crying usually unrelated to a true emotion or a congruent mood. An extremely rare form is the "fou rire prodromique" (prodrome of crazy laughter), a

\footnotetext{
* Correspondence: adrianadulamea@gmail.com

"University of Medicine and Pharmacy "Carol Davila", Bucharest, Romania

${ }^{2}$ Neurology Department Fundeni Clinical Institute, Sos Fundeni nr 258, sector

2, Bucharest 022328, Romania

Full list of author information is available at the end of the article
}

pathological manifestation reported in association to carotid or vertebrobasilar brain ischemia. Cases of PLC were described in association with cerebrovascular disease, amyotrophic lateral sclerosis, multiple system atrophy-cerebellar type, multiple sclerosis, Parkinson's disease, traumatic brain injury, dementia, migraine, progressive supranuclear palsy and mass lesions especially in the cerebellopontine junction. PLC must be differentiated from emotional instability characteristic to pseudobulbar syndrome, from gelastic epilepsy and psychiatric disorders. We report the case of a man presenting recurrent pathological laughter episodes preceding transient ischemic attacks. 


\section{Case presentation}

A fifty-nine-year-old right-handed man, former smoker, with history of chronic alcohol intake, arterial hypertension, mixed hyperlipidemia, two recent left middle cerebral artery ischemic strokes (left temporo-insular and left frontal lacunar infarcts) manifested as right hemiparesis and aphasia, right focal motor seizures, gastric ulcer secondary to excessive use of nonsteroidal antiinflammatory drugs for occipital headache was admitted for episodes of PLC started $6 \mathrm{~h}$ before admission. The episodes lasted approximately $2 \mathrm{~min}$, consisting of accelerated breathing, emission of guttural, snoring sounds, frowning of the eyebrows, followed by laughter accompanied by motor restlessness of all four limbs; the patient was able to walk with assistance but was unresponsive during these episodes. An additional movie file shows this in more detail [see Additional file 1]. The patient denied any automatisms, loss of consciousness, loss of memory, or altered mental status. He also denies any sense of mirth during these episodes. On admission the patient's home medication were clopidogrel, carbamazepin, gabapentin, pantoprazole, and quinapril. Initial examination was notable for confusion, right upper motor neuron facial weakness, 4/5 right hemiparesis, and a mixed aphasia. Between episodes of PLC there were pauses of about $10 \mathrm{~min}$.

The differential diagnosis was made between gelastic seizures and episodes of pathological laughter as manifestation of repeated transient ischemic attacks (TIA's). The pseudobulbar laughter was excluded because the patient didn't present any emotional incontinence outside the pathological laughter episodes. Brain scan showed left temporo-insular and left frontal chronic lacunar infarcts. Electroencephalography (EEG) performed during and after laughter episodes revealed no spikewave activity (Fig. 1). Analysis of the cerebrospinal fluid specimen revealed a protein level of $0.3 \mathrm{~g}$ per liter, a glucose concentration of $72.8 \mathrm{mg}$ per deciliter, a white blood cells count of 5 per cubic millimeter, polymorphonuclears of 2 per cubic millimeter, monocytes of 3 per cubic millimeter, no red blood cells. Routine laboratory blood test showed elevated uric acid of $8 \mathrm{mg}$ per deciliter, slightly elevated gamma-glutamyl transferase of 57

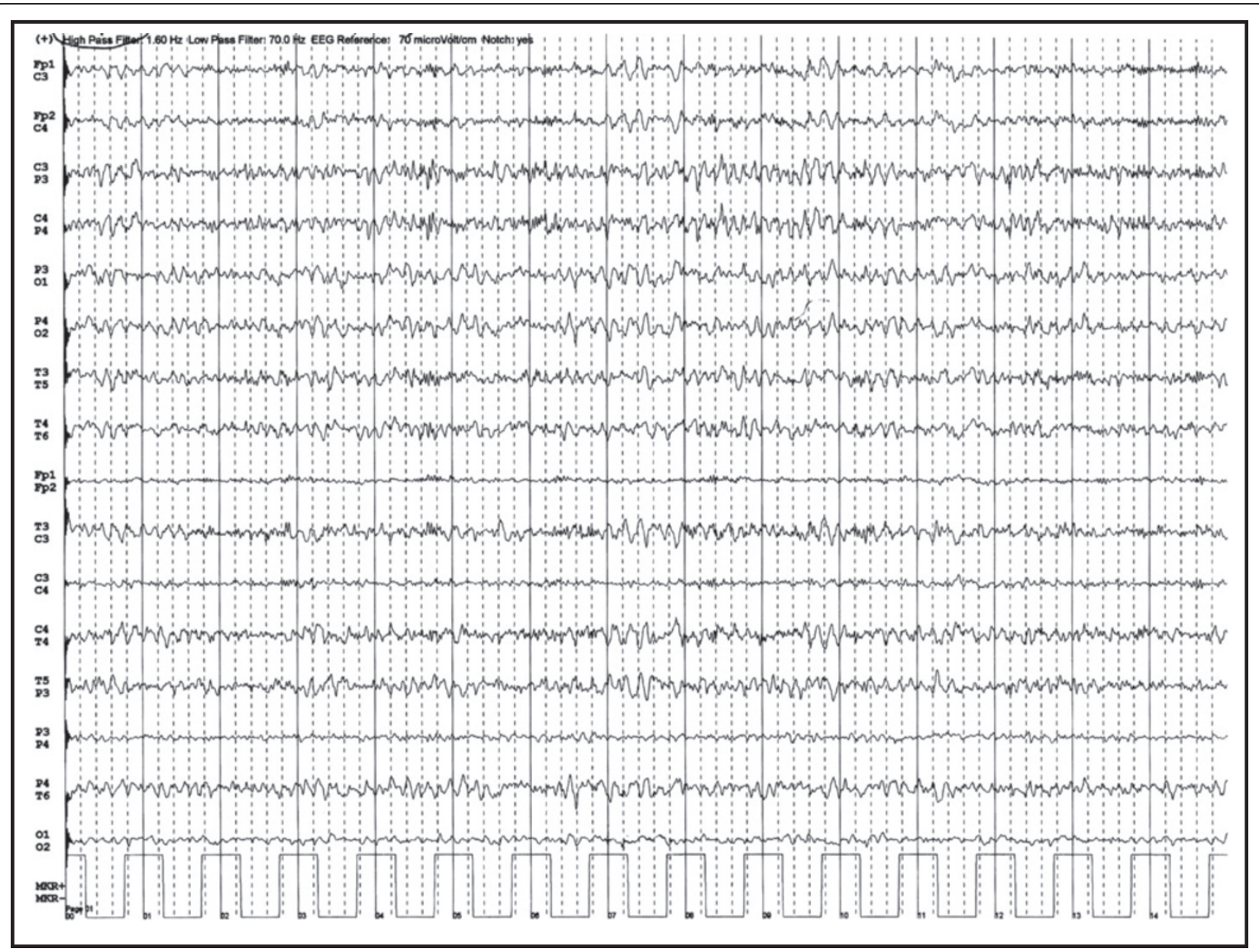

Fig. 1 EEG performed during PLC episodes showed no spike wave activity only slow waves on the derivations on the right side 
U per liter, increased glucose level of $136 \mathrm{mmol}$ per liter, increased lactate dehydrogenase of $236 \mathrm{mmol}$ per liter, increased triglycerides of $152.3 \mathrm{mg}$ per deciliter, increase white blood cells count of 10790 per cubic millimeter with increased neutrophils blood count of 8150 per cubic millimeter, all the other blood tests were normal. The patient was treated initially with clopidogrel, atorvastatin, diazepam and phenytoin during acute PLC episodes and clopidogrel, atorvastatin, carbamazepine $600 \mathrm{mg} /$ day and levetiracetam $1000 \mathrm{mg} /$ day as maintenance treatment, but the PLC episodes continued for 3 days with a shorter duration and a longer period between them. Brain magnetic resonance imaging (MRI), performed 5 days after symptoms onset, showed lacunar infarcts localized in the left lenticular-capsular-thalamic area associated with gliotic changes; multiple round lesions in the cortical-subcortical and in the deep white matter bilateral frontal-parietal-occipital, with T2 hyperintensity, T1 isointensity and no diffusion changes (Figs. 2 and 3). Based on symptoms, neurological examination and investigations the diagnosis of PLC as prodromal manifestation of TIA's was made, heparin treatment was started and subsequently PLC episodes disappeared. However the gelastic seizures hypothesis could not be ruled out since EEG may not show spikewave activity if the lesion is subcortical. Therefore the authors decided that antiepileptic treatment should be continued. The patient underwent a cognitive and psychological examination that did not reveal a cognitive dysfunction or a mood disorder. Carotid ultrasound showed non-hemodynamically significant plaque in the left carotid bulb. Transthoracic echocardiography showed moderate degenerative mitral stenosis (mitral valve area $=1.3 \mathrm{~cm}^{2}$, mean gradient $8 \mathrm{mmHg}$ ), mild mitral regurgitation, dilated left atrium, mild pulmonary hypertension and normal systolic left ventricular function and dimensions. Transesophageal echocardiography revealed, in addition to transthoracic echocardiography, left atrial spontaneous echo contrast (grade 3+), but no thrombus in left atrial appendage. Intra-cardiac defects with right-to-left shunt were also excluded. Some mobile atherosclerotic plaques on ascending aorta and initial part of the aortic arch were present, but no clear arguments for potential embolisation could be sustained. Given the degree of mitral stenosis, anticoagulation with acenocumarol was started, and clopidogrel was continued. Some concerns about this association were raised related to history of superior digestive hemorrhage of the patient, so clopidogrel $75 \mathrm{mg}$ daily was preferred to low dose aspirin. The patient continued treatment with acenocumarol (INR $=2-3$ ), clopidogrel $75 \mathrm{mg}$ /day, atorvastatin $20 \mathrm{mg} /$ day, carbamazepin $600 \mathrm{mg} /$ day, gabapentin $900 \mathrm{mg} /$ day and was discharged fully recovered. A video EEG was performed that showed no spike-waves only slow waves on the right side derivations (Fig. 4). A month later the patient started to present multiple left carotid and vertebrobasilar TIA's despite correct anticoagulant treatment (INR in the therapeutic range). These ongoing embolic events led to treatment with mechanical valve replacement, afterwards the patient was completely asymptomatic.

\section{Discussion}

Emotional experience is a subjective feeling during an emotional event. Emotional expression is the objective behavior that is expressed during such event, including changes in autonomic functions as heart rate and skeletal movements such as facial expression. The
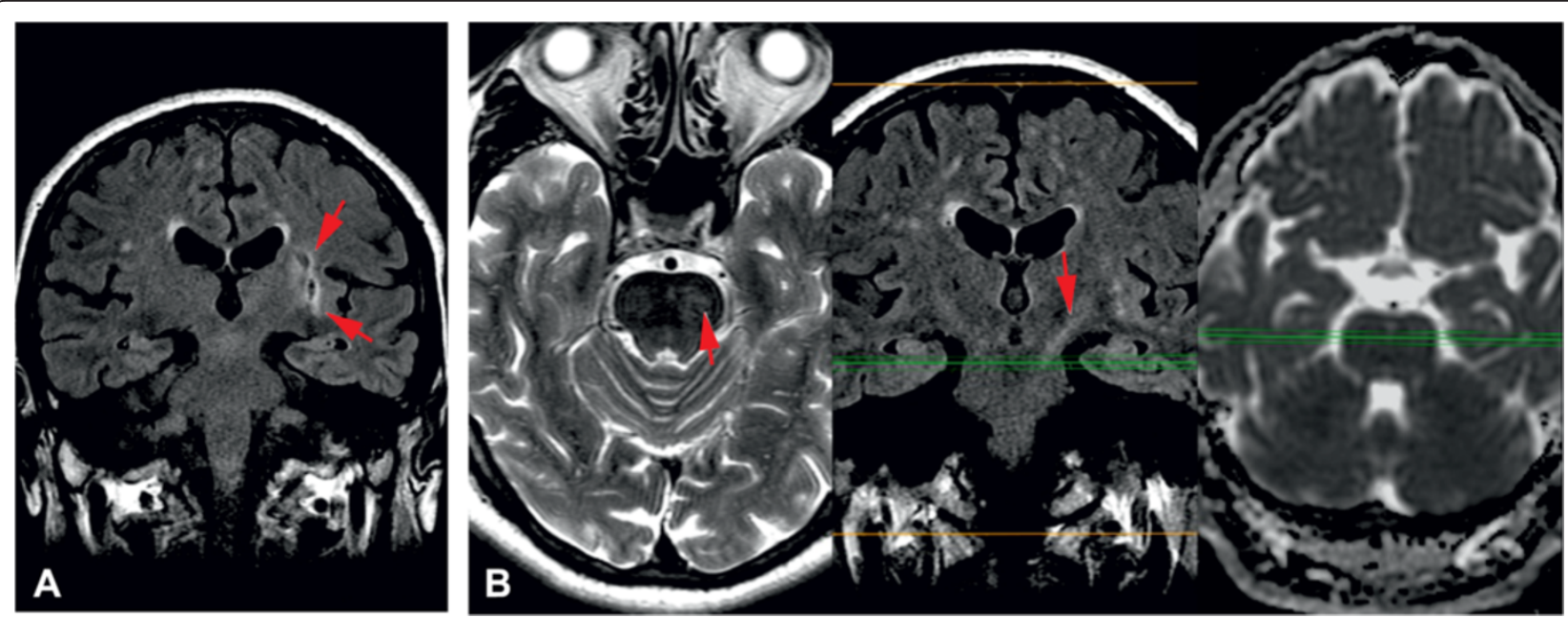

Fig. 2 A, B Polygonal left side area intra- and supranuclear hyperintense T2, hypointense with hyperintense periphery on FLAIR images, which interface pyramidal fibers in the posterior arm of internal capsule leeding to Wallerian degeneration of them - left lateral pontine dots that apare hyperintense on $\mathrm{T} 2$ and FLAIR images, without restricted diffusion 


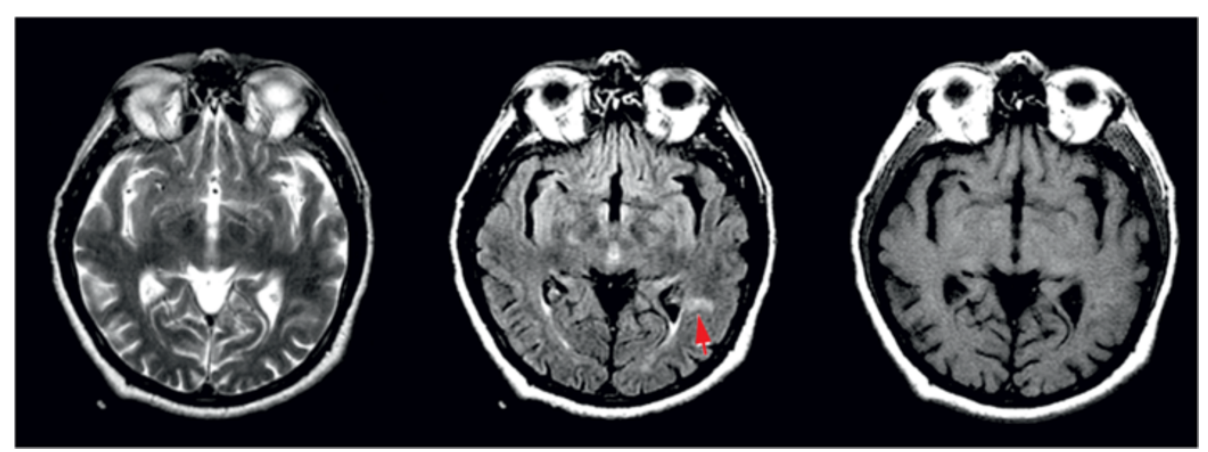

Fig. 3 Paraventricular left temporal poligonal area with reduced dimensions between exams - area of ischemia in the subacute stage hyperintense on $\mathrm{T} 2$ and FLAIR, hypointense on $\mathrm{T} 1$ without restricted diffusion

experience and the expression of an emotion depends on the cognitive appraisal of the emotional stimuli which are triggering it. While emotional experience is disturbed in patients with psychiatric conditions (e.g. mood disorders), patients with neurological disorders suffer from dysregulation of emotional expression, mostly the expressions of laughter or crying, in the absence of a congruent feeling. Unlike mood disorders, inappropriate emotional expression in these patients is not a sustained phenomenon but a paroxysmal and episodic one.

According to Poeck's criteria [2], PLC is laughter that arises: (1) in response to non-specific stimuli; (2) in the absence of a corresponding change in affect; (3) in the absence of voluntary control of the extent or duration of the episode; and (4) in the absence of a corresponding change in mood lasting beyond the actual laughing. PLC is a disorder of emotional expression, not a disturbance of feelings, and can be distinguished from mood disorders [3].

To summarize the results of many studies investigating the neural correlates of laughter and humor, the expression of laughter seems to depend on two partially independent neuronal pathways [4]. The first of these, excitatory, "involuntary" or "emotionally driven" system, involves the amygdala, temporal cortex, thalamic/hypoand subthalamic areas and the dorsal/tegmental brainstem. The second, inhibitory, "voluntary" system originates in the premotor/frontal opercular areas and leads through the motor cortex and pyramidal tract to the ventral brainstem [5].

These systems appear to be coordinated by a laughter-coordinating center in the dorsal upper pons, central coordinator of the nuclei that innervate the muscles involved in expression of emotion, phonation, rhythmic clonic expiration and facial expression. The mesencephalic central gray matter acts as relay station between descending limbic diencephalic tracts and bulbar effector nuclei and via the annulo-olivary tract to the cerebellum that exercises a modulating effect on all these expressions [6-8]. Parvizi et al. [6] suggested that cerebellum plays an important role in modulating laughter and crying to specific context; it also sets the threshold at which the induction - effector apparatus responds to a stimulus. These modulatory cerebellar actions would occur automatically as a result of learning.

The causes of PLC syndrome can be classified in two groups: altered behavior with unmotivated happiness (Angelman syndrome, schizophrenia, manias, dementia) and interference with the inhibitory/excitatory mechanisms (gelastic epilepsy, fou rire prodromique in strokes, multiple sclerosis, amyotrophic lateral sclerosis, Parkinson's disease and Parkinson-plus, traumatic injuries, tumours) [9-11].

Gelastic epilepsy (from the Greek "gelos" meaning laughter) refers to those relatively rare seizures in which laughter is the cardinal symptom. These seizures can consist exclusively of laughing but often occur in association with general autonomic arousal and automatisms of movement and/or disturbed states of consciousness [12-17]. Several papers reported other symptoms accompanying less frequent this ictal laughter, such as perambulation [18] and micturition [19]. Some patients report pleasant feeling which include exhilaration or mirth [20-22], other patients experience the attacks of laughter as inappropriate and feel no positive emotions during their laughter [23-25]. The lesions incriminated in gelastic seizures are located in the hypothalamus especially hypothalamic hamartomas [14, 15, 24, 26-28], the frontal poles [21, 29] and the temporal poles [30]. Sethi and Rao [31] reported a patient with episodes of epileptic laughter, crying and running occurring alone or in combination. The patient was found to have a discrete, well circumscribed tumour of the left temporal lobe.

Fou rire prodromique [32] is a very rare condition in which unmotivated, inappropriate laughter occurs as the first symptom of cerebral ischemia. This uncontrollable laughter may be followed by giggling [33] or crying [34] and typical symptoms of stroke in the territory of carotid 


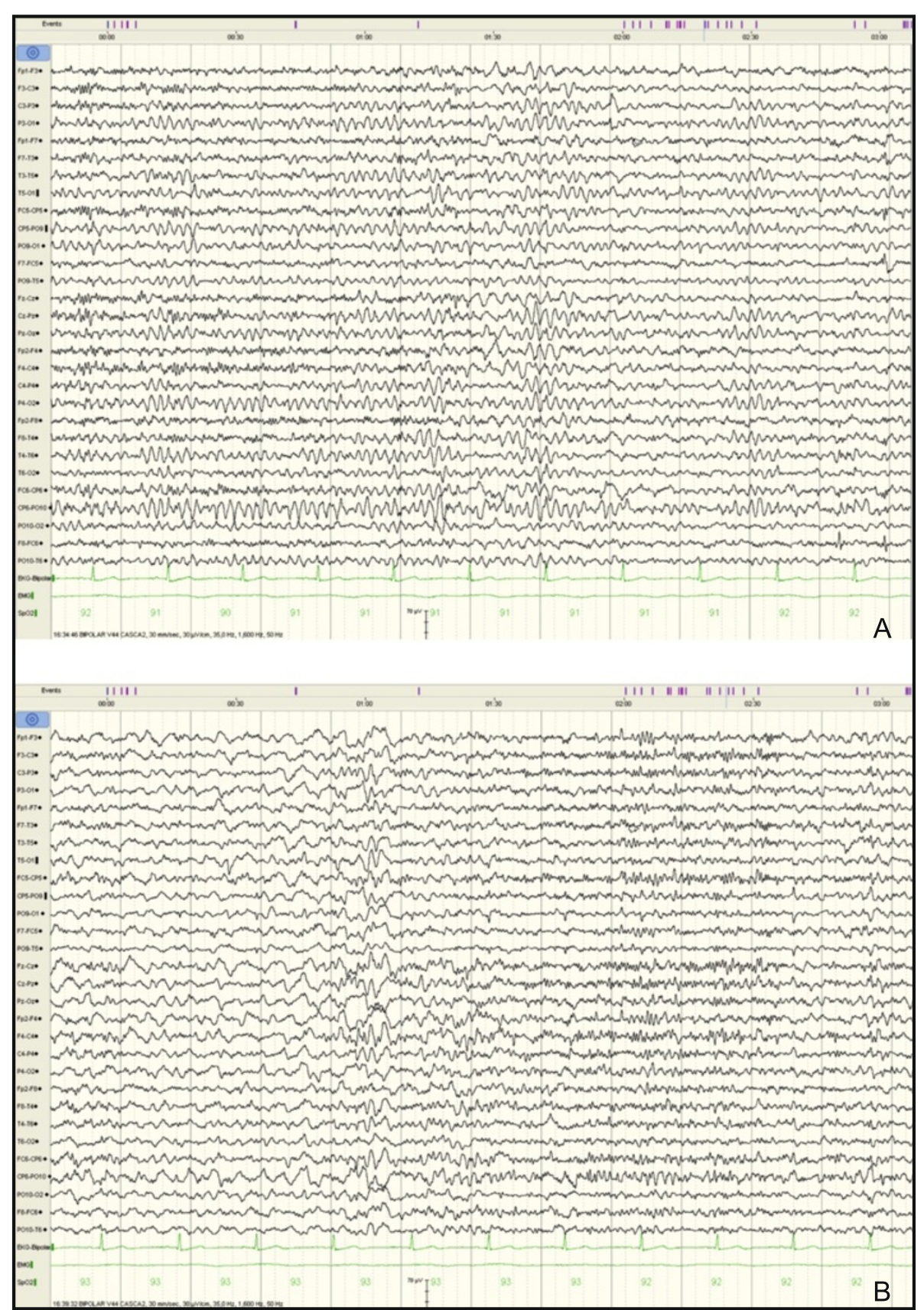

Fig. 4 A, B Video EEG during awake state and during sleep without spike-waves anomalies but with some slow waves especially on the right side during sleep

or basilar artery. Lesions associated with "fou rire prodromique" have been found in: (i) base of the pons bilaterally with no involvement of the tegmentum [33]; ii) left parahippocampal gyrus, the left posterolateral thalamus and adjacent parts of the internal capsule, with no involvement of the hypothalamus, the hippocampus or the amygdala [35]; (iii) left lenticular and caudate nuclei, with involvement of the anterior insula [36]; (iv) the area supplied by the right middle cerebral artery (non- dominant cerebral hemisphere) [37], (v) simultaneous bilateral capsular genu infarction [38], (vi) midbrain infarction [39], (vii) left middle cerebral artery territory (dominant cerebral hemisphere) [40], left pontine infarction due to basilar artery stenosis [41].

Parvizi J et al. (2007) [42] described a case of pathological laughter in the absence of congruent changes of mood in a patient with cerebellar type of multiple system atrophy (MSA-C). Nine patients out of 27 other 
patients with MSA-C revealed episode of pathological laughter, crying, or both. Authors finding of about $36 \%$ occurrence suggests that the problem of dysregulation of emotional expression is more prevalent in MSA-C than the paucity of reports in the literature suggests and it is consistent with the view that the cerebellum and its interconnected structures may be involved in the regulation of emotional expression.

Olney N.T. et al. (2011) [43] compared amyotrophic lateral sclerosis (ALS) patients that presented episodes of PLC with ALS patients who did not have such episodes. The episodes were induced by contextually appropriate stimuli and associated with strong experiences of emotion that produced greater facial and physiological activation. The authors concluded that PLC represents activation of all channels of emotional responding (i.e. behavioural, physiological and subjective). Furthermore, they support previously advanced theories [44] that, rather than being associated with general emotional hyperreactivity, this disorder may be due to dysfunction in frontal neural systems that support voluntary regulation of emotion. Gallagher J.P. (1989) [45] examined 73 ALS patients of whom 36 had experienced episodes of PLC and nearly all of these developed bulbar involvement with the illness.

Cavanna A.E. et al. (2010) [46] described 8 patients with Gilles de la Tourette syndrome presenting PLC as part of their tic repertoire. All patients experienced PLC as a simple phonic tic, accompanied by characteristic premonitory urges and significant impairment in social interactions. The authors suggest that the pathophysiological mechanisms underlying the expression of PLC as a tic could involve a dissociation between fronto-striatal and limbic networks.

PLC is a component of global behavior pattern in Angelman syndrome. It has been suggested that the speech/language deficit in Angelman syndrome cannot be accounted for solely by mental retardation and that oral-motor dyspraxia and deficits in social interactions are quite characteristic of the syndrome. Peters S.U. et al. (2011) [47] showed that, in this syndrome, there is a decreased/delayed myelination, decreased axonal density diameter or aberrant axonal organization suggesting a generalized white matter alteration throughout the brain especially in temporal pathways and left arcuate fasciculus.

PLC was also described in Parkinson's disease, multiple sclerosis, traumatic brain injuries, dementia, migraine, progressive supranuclear palsy [5], acute disseminated encephalomyelitis [48] or mass lesions (abscess in the anterior paramedian pons [49], cerebellar tumour [50], trigeminal schwannoma [51], frontal glioblastoma [52], pontine glioma [53]).

PLC in multiple sclerosis is the result either of isolated lesions to specific areas of the brain (in medulla oblongata and the mesencephalon [54], clinically isolated syndrome with pontine lesion [55]) or the consequence of an extensive diffuse involvement of the brain especially of the prefrontal cortex producing a complex neuropsychological impairment [56-58].

\section{Conclusions}

This case illustrates the difficulty of distinguishing between TIA's and gelastic seizures in cases of PLC. The absence of automatisms and spike-wave activity on EEG during episodes, the lack of efficacy of the antiepileptic treatment and the remission of episodes after anticoagulation and mitral valve replacement were arguments that supported the diagnosis of TIA's. However a plausible assumption could be also that PLC episodes were generated by gelastic seizures caused by repeated ischemic episodes due to multiple TIA's. In our patient the identification of multiple lacunar infarcts in the capsular area and cortical-subcortical frontal-parietal areas bilaterally as well as in the left pontine region is in concordance with the hypothesis of a complex system of emotion control which involves bilateral frontal and temporal lobes, the internal capsule, thalamic and subthalamic areas, upper brainstem, pons and cerebellum. PLC episodes have been reported in association with very diverse brain disorders. This case report showed that PLC is a rare clinical presentation of cardioembolic strokes.

\section{Patient consent}

Written informed consent was obtained from the patient for publication of this case report and any accompanying images. A copy of the written consent is available for review by the editor of this journal.

\section{Additional files}

Additional file 1: Episode of pathological laughter that preceded transient ischemic attacks in the territory of the left carotid artery. (MP4 11.3 MB)

\section{Abbreviations}

PLC: Pathological laughing and crying; IEED: Involuntary emotional expression disorder; EL: Emotional lability; TIA's: Transient ischemic attacks; MRI: Magnetic resonance imaging; EEG: Electroencephalography; MSAC: Cerebellar type of multiple system atrophy; ALS: Amyotrophic lateral sclerosis.

\section{Competing interests}

The authors declare that they have no competing interests.

Authors' contributions

AOD, CM, IM, VI contributed to data acquisition. AOD drafted and reviewed the manuscript. All authors approved the version to be published.

\section{Acknowledgements}

We thank to dr. Emil Tufanoiu and dr. Claudia Pavel who participated to the diagnosis and treatment of this patient.

We thank to Ms. Monica Marinescu who provided the English version revision of the text. 


\section{Author details}

"University of Medicine and Pharmacy "Carol Davila", Bucharest, Romania.

${ }^{2}$ Neurology Department Fundeni Clinical Institute, Sos Fundeni nr 258, sector 2, Bucharest 022328, Romania. ${ }^{3}$ Cardiology Department Emergency Institute for Cardiovascular Diseases "Prof. Dr. C. C. Iliescu", Bucharest, Romania. ${ }^{4}$ Neurology Department University Emergency Hospital, Bucharest, Romania. ${ }^{5}$ Radiology Department Sanador Hospital, Bucharest, Romania.

Received: 13 December 2014 Accepted: 2 October 2015 Published online: 12 October 2015

\section{References}

1. Lauterbach EC, Cummings JL, Kuppuswamy PS. Toward a more precise, clinically_informed pathophysiology of pathological laughing and crying. Neurosci Biobehav Rev. 2013;37(8):1893-916.

2. Poeck K. Pathophysiology of emotional disorders associated with brain damage. In: Vinken PJ, Bruyn GW, editors. Handbook of clinical neurology, vol. 3. Amsterdam: Elsevier; 1969. p. 343-67.

3. Poeck K. Pathological laughter and crying. In: Frederik S, editor. Handbook of clinical neurology, Volume 1. Amsterdam: Elsevier; 1985. p. 219-25.

4. Wild B, Rodden FA, Grodd W, Ruch W. Neural correlates of laughter and humour. Brain. 2003;126:2121-38.

5. Parvizi J, Coburn KL, Shillcutt SD, Coffey CE, Lauterbach EC, Mendez MF. Neuroanatomy of pathological laughing and crying: a report of the American Neuropsychiatric Association Committee on Research. Neuropsychiatry Clin Neurosci. 2009;21:75-87.

6. Parvizi J, Anderson SW, Martin CO, Damasio H, Damasio AR. Pathological laughter and crying. A link to cerebellum. Brain. 2001;124:1708-19.

7. Davison C, Kelman H. Pathological laughter and crying. Arch Neurol Psychiatry. 1939;42(4):595-643.

8. Provine RR. Laughter: a scientific investigation. New York: Viking; 2000. p. 23-53. 158-62.

9. Gardner H, Ling PK, Flamm L, Silverman J. Comprehension and appreciation of humorous material following brain damage. Brain. 1975;98:399-412.

10. Shammi P, Stuss DT. Humour appreciation: a role of the right frontal lobe. Brain. 1999;122:657-66.

11. Arias M. Neurology of laughter and humour: pathological laughing and crying. Rev Neurol. 2011;53(7):415-21.

12. Wilson SAK. Some problems in neurology, No. II. Pathological laughing and crying. J Neurol Psychopath. 1924;4:299-333.

13. Berkovic SF, Andermann F, Melanson D, Ethier R, Feindel W, Gloor P. Hypothalamic hamartomas and ictal laughter: evolution of a characteristic epileptic syndrome and diagnostic value of magnetic resonance imaging. Ann Neurol. 1988;23:429-39.

14. Cascino GD, Andermann F, Berkovic SF, Kuzniecky Rl, Sharbrough FW, Keene $\mathrm{DL}$, et al. Gelastic seizures and hypothalamic hamartomas: evaluation of patients undergoing chronic intracranial EEG monitoring and outcome of surgical treatment. Neurology. 1993;43:747-50.

15. Valdueza JM, Cristante L, Dammann O, Bentele K, Vortmeyer A, Saeger W, et al. Hypothalamic hamartomas: with special reference to gelastic epilepsy and surgery. Neurosurgery. 1994;34:949-58.

16. Cerullo A, Tinuper P, Provini F, Contin M, Rosati A, Marini $C$, et al. Autonomic and hormonal ictal changes in gelastic seizures from hypothalamic hamartomas. Electroencephalogr Clin Neurophysiol. 1998;107:317-22

17. Striano S, Meo R, Bilo L, Cirillo S, Nocerino C, Ruosi P, et al. Gelastic epilepsy: symptomatic and cryptogenic cases. Epilepsia. 1999;40:294-302.

18. Jandolo B, Gessini L, Occhipinti E, Pompili A. Laughing and running as manifestation of early traumatic epilepsy. Eur Neurol. 1977;15:177-82.

19. Tasch E, Cendes F, Li LM, Dubeau F, Montes J, Rosenblatt B, et al. Hypothalamic hamartomas and gelastic epilepsy: a spectroscopic study. Neurology. 1998:51:1046-50.

20. Jacome DE, McLain Jr LW, FitzGerald R. Postural reflex gelastic seizures. Arch Neurol. 1980:37:249-51.

21. Arroyo S, Lesser RP, Gordon B, Uematsu S, Hart J, Schwerdt P, et al. Mirth, laughter and gelastic seizures. Brain. 1993;116:757-80.

22. Iwasa H, Shibata T, Mine S, Koseki K, Yasuda K, Kasagi Y. et al. Different patterns of dipole source localization in gelastic seizure with or without a sense of mirth. Neurosci Res. 2002, 43(1):23-29.
23. Assal G, Majdalani A, Gautier JC. Gelastic epilepsy. Probable diencephalic hamartoma. [French]. Rev Neurol Paris. 1993:149:291-3.

24. Munari C, Kahane P, Francione S, Hoffmann D, Tassi L, Cusmai R, et al. Role of the hypothalamic hamartoma in the genesis of gelastic (a video-stereo-EEG study). Electroencephalogr Clin Neurophysiol. 1995;95:154-60

25. Sturm JW, Andermann F, Berkovic SF. 'Pressure to laugh': an unusual epileptic symptom associated with small hypothalamic hamartomas. Neurology. 2000;54:971-3.

26. Kuzniecky R, Guthrie B, Mountz J, Bebin M, Faught E, Gilliam F, et al. Intrinsic epileptogenesis of hypothalamic hamartomas in gelastic epilepsy. Ann Neurol. 1997:42:60-7.

27. Georgakoulias N, Vize C, Jenkins A, Singounas E. Hypothalamic hamartomas causing gelastic epilepsy: two cases and a review of the literature. Seizure. 1998;7:167-71.

28. Unger F, Schrottner O, Haselsberger K, Korner E, Ploier R, Pendl G. Gamma knife radiosurgery for hypothalamic hamartomas in patients with medically intractable epilepsy and precocious puberty. Report of two cases. J Neurosurg. 2000;92:726-31.

29. Iannetti P, Spalice A, Raucci U, Atzei G, Cipriani C. Gelastic epilepsy: videoEEG, MRI and SPECT characteristics. Brain Dev. 1997:19:418-21.

30. Coria F, Bahillo Marcos E, Moral Blanco M, Garcia Gutierrez P, Oritz Saenz de Santa Maria R. Late onset isolated gelastic epilepsy secondary to entrapment of the right temporal horn. Neurologia. 2000;15:204-7.

31. Sethi PK, Rao TS. Gelastic, quiritarian, and cursive epilepsy. A clinicopathological appraisal. J Neurol Neurosurg Psychiatry. 1976;39(9):823-8.

32. Féré MC. Le fou rire prodromique. Rev Neurol (Paris). 1903;11:353-8.

33. Wali GM. 'Fou rire prodromique' heralding a brainstem stroke. J Neuro Neurosurg Psychiatry. 1993;56:209-10.

34. Badt B. Lachen als erstes symptom eines apoplektischen Insultes. Zges Neurol Psychiat. 1927;110:297-300.

35. Ceccaldi M, Milandre L. A transient fit of laughter as the inaugural symptom of capsular-thalamic infarction. Neurology. 1994;44:1762

36. Carel C, Albucher JF, Manelfe C, Guiraud-Chaumeil B, Chollet F. Fou rire prodromique heralding a left internal carotid artery occlusion. Stroke 1997;28:2081-3.

37. Lago A. Fou rire prodromique and ischemic stroke. Stroke. 1998;29:1067-8.

38. Uzunca I, Utku U, Asil T, Celik Y. "Fou rire prodromique" associated with simultaneous bilateral capsular genu infarction. J Clin Neurosci. 2005;12(2):174-5.

39. Dabby R, Watemberg N, Lampl Y, Eilam A, Rapaport A, Sadeh M. Pathological laughter as a symptom of midbrain infarction. Behav Neurol. 2004;15(3-4):73-6

40. Garg RK, Misra S, Verma R. Pathological laughter as heralding manifestation of left middle cerebral artery territory infarct: case report and review of literature. Neurol India. 2000;48(4):388-90.

41. Tei $H$, Sakamoto $Y$. Pontine infarction due to basilar artery stenosis presenting as pathological laughter. Neuroradiology. 1997;39(3):190-1.

42. Parvizi J, Joseph J, Press DZ, Schmahmann JD. Pathological laughter and crying in patients with multiple system atrophy-cerebellar type. Mov Disord. 2007:22:798-803.

43. Olney NT, Goodkind MS, Lomen-Hoerth C, Whalen PK, Williamson CA, Holley DE, et al. Behaviour, physiology and experience of pathological laughing and crying in amyotrophic lateral sclerosis. Brain. 2011:134(Pt 12):3458-69.

44. McCullagh S, Moore M, Gawel M, Feinstein A. Pathological laughing and crying in amyotrophic lateral sclerosis: an association with prefrontal cognitive dysfunction. J Neurol Sci. 1999:169(1-2):43-8.

45. Gallagher JP. Pathologic laughter and crying in ALS: a search for their origin Acta Neurol Scand. 1989:80(2):114-7.

46. Cavanna AE, Ali F, Leckman JF, Robertson MM. Pathological laughter in Gilles de la Tourette syndrome: an unusual phonic tic. Mov Disord. 2010;25(13):2233-9

47. Peters SU, Kaufmann WE, Bacino CA, Anderson AW, Adapa P, Chu Z, et al. Alterations in white matter pathways in Angelman syndrome. Dev Med Child Neurol. 2011:53(4):361-7.

48. Chaundhry N, Puri V, Patidar Y, Khwaja GA. Pathological laughter associated with paroxysmal kinesigenic dyskinesia: a rare presentation of acute disseminated encephalomyelitis. Epilepsy Behav Case Rep. 2013;1:14-9.

49. Elyas AE, Bulters DO, Sparrow OC. Pathological laughter and crying in patients with pontine lesions. Neurosurg Pediatr. 2011;8(6):544-7. 
50. Famularo G, Corsi FM, Minisola G, De Simone C, Nicotra GC. Cerebellar tumour presenting with pathological laughter and gelastic syncope. Eur J Neurol. 2007;14(8):940-3.

51. Jagetia A, Pratap Kumar N, Singh D, Sinha S. Pathological laughter in trigeminal schwannoma: case report and review of the literature. Neurosurg Rev. 2006;29(4):348-52.

52. Tsutsumi S, Yasumoto Y, Ito M. Pathological laughter caused by frontal glioblastoma: case report. Neurol Med Chir (Tokyo). 2008:48(7):307-10

53. Hargrave DR, Mabbott DJ, Bouffet E. Pathological laughter and behavioural change in childhood pontine glioma. J Neurooncol. 2006;77(3):267-71.

54. de Seze J, Zephir H, Hautecoeur P, Mackowiak A, Cabaret M, Vermersch P. Pathologic laughing and intractable hiccups can occur early in multiple sclerosis. Neurology. 2006;67(9):1684-6.

55. Kocer B, Oner Y, Batur H, Nazliel B, Cengiz B, Tali T. Pathological laughing as a manifestation in a clinically isolated brainstem syndrome: a case report J Neuroimaging. 2009;19(3):291-4.

56. Feinstein A, O'Connor P, Gray T, Feinstein K. Pathological laughing and crying in multiple sclerosis: a preliminary report suggesting a role for the prefrontal cortex. Mult Scler. 1999:5(2):69-73.

57. Feinstein A, Feinstein K, Gray T, O'Connor P. Prevalence and neurobehavioral correlates of pathological laughing and crying in multiple sclerosis. Arch Neurol. 1997;54(9):1116-21.

58. Benedict RH, Carone DA, Bakshi R. Correlating brain atrophy with cognitive dysfunction, mood disturbances, and personality disorder in multiple sclerosis. J Neuroimaging. 2004;14(3 Suppl):36S-45S.

\section{Submit your next manuscript to BioMed Central and take full advantage of:}

- Convenient online submission

- Thorough peer review

- No space constraints or color figure charges

- Immediate publication on acceptance

- Inclusion in PubMed, CAS, Scopus and Google Scholar

- Research which is freely available for redistribution 